\title{
EDUCAÇÃO DO CAMPO COMO CATEGORIA TEMÁTICA EM REVISTAS (2015-2020)
}

\author{
Arlete Ramos dos Santos ${ }^{1}$ \\ Jamile de Souza Soares² \\ Edmacy Quirina de Souza ${ }^{3}$
}

\begin{abstract}
RESUMO
Este texto traz o estado da arte sobre a temática Educação do Campo em quatro revistas nacionais: Revista Educação \& Formação, Revista Exitus, Revista Práxis Educacional e Revista Tempos e Espaços em Educação, de acordo o recorte temporal 2015-2020. Nas quatro revistas foi encontrado um total de 41 publicações, sendo que as publicações aconteceram em maior número em 2017, com 19 artigos que tratam da temática Educação do Campo. A partir do estudo, possibilitou-se analisar que a revista que possui mais publicações sobre a temática pesquisada é a Práxis Educacional com 24 artigos, seguida pela Revista Exitus com dez, Revista Educação \& Formação com quatro, e por fim, a Revista Tempos e Espaços em Educação com três. Assim, diversas contribuições foram encontradas nas produções, que abarcam questões relacionadas às políticas públicas, práticas pedagógicas, movimentos sociais, Escolas Família Agrícola, formação em assentamentos e trajetórias de vida. Desse modo, as produções encontradas, são muito relevantes visto que, contribuem para nos ajudar a pensar as políticas públicas e a prática pedagógica de uma educação para o campo.
\end{abstract}

Palavras-chave: Educação do Campo. Educação Rural. Movimentos Sociais.

\footnotetext{
1 Pós-Doutorado em Educação e Movimentos Sociais pela UNESP, Doutora e Mestre em Educação (FAE/UFMG). Professora Titular da Universidade Estadual do Sudoeste da Bahia (UESB); Professora do Programa de Pós-Graduação em Educação da UESB (PPGEd/Uesb); Prof ${ }^{a}$. do PPGE/UESC; Coordenadora do Grupo de Estudos e Pesquisas em Movimentos Sociais, Diversidade e Educação do Campo e Cidade - Gepemdecc/CNPq. Orcid iD: https://orcid.org/0000-0003-0217-3805. E-mail: arlerp@hotmail.com

2 Pedagoga pela UNEB; Mestranda do Programa de Pós-Graduação, Mestrado em Educação da UESB (PPGEd/Uesb); Membro do Grupo de Estudos e Pesquisas em Movimentos Sociais, Diversidade e Educação do Campo e Cidade - Gepemdecc/CNPq. Orcid iD: https://orcid.org/0000-0003-3732-5274. E-mail: jamsouza_2016@hotmail.com 3 Doutorado em Educação pela UFSCar; Professora Adjunta da Universidade Estadual do Sudoeste da Bahia; Coordenadora do Colegiado de Pedagogia do DCHEL/UESB. Membro do Grupo de Estudos e Pesquisas em Movimentos Sociais, Diversidade e Educação do Campo e Cidade - Gepemdecc/CNPq. Orcid iD: https://orcid.org/0000-0002-6712-1021. Email: macy.souza@hotmail.com
} 


\title{
RURAL EDUCATION AS A THEMATIC CATEGORY IN EDUCATION JOURNALS
}

(2015-2020)

\begin{abstract}
This text brings the state of the art on the theme Rural Education in four national education journals: the Educação \& Formação Journal, the Exitus Journal, the Práxis Educacional Journal and the Tempos e Espaços em Educação Journal. From 2015 to 2020, a total of 41 articles on this theme were found in these journals, most of which were published in 2017 (19 articles). The results of the study indicate that the Praxis Educacional Journal has more publications on the researched theme (24 articles), followed by the Exitus Journal (10 articles), the Educação \& Formação Journal (4 articles), and finally, the Tempos e Espaços em Educação Journal (3 articles). Various contributions were found in these publications, which cover issues related to public policies, pedagogical practices, social movements, agricultural family schools, teacher education in settlements and life trajectories. These academic productions are considered relevant since they aid reflection on the public policies and the pedagogical practices of Rural Education.
\end{abstract}

Keywords: Rural Education. Education in rural areas. Social Movements.

\section{EDUCACIÓN DE CAMPO COMO CATEGORÍA TEMÁTICA DE REVISTAS (2015- 2020)}

\section{RESUMEN}

Este texto discute el estado del arte sobre el tema Educación del campo en cuatro revistas nacionales: Revista Educação \& Formação, Revista Exitus, Revista Práxis Educacional y Revista Tempos e Espaços em Educação, según el marco de tiempo 2015-2020. Se encontraron un total de 41 publicaciones en las cuatro revistas con el mayor número de publicaciones en 2017 y 19 artículos relacionados con el tema de Educación de campo. A partir del estudio, se encontró que la revista que tiene más publicaciones sobre el tema es Educational Praxis con 24 artículos, seguida de Exitus Magazine con 10, Revista Educación y Formación 4, y finalmente, Revista Tiempos y Espacios en Educación con 3. Asimismo, existen varias contribuciones en temas relacionados con políticas públicas, prácticas pedagógicas, movimientos sociales, escuelas de familias agrícolas, capacitación en asentamientos y trayectorias de vida. Se concluye que las producciones encontradas son muy relevantes, ya que coadyuvan al pensamento sobre políticas públicas y la práctica pedagógica de la educación para el campo.

Palabras clave: Educación del Campo. Educación Rural. Movimientos Sociales.

\section{INTRODUÇÃO}

O presente trabalho tem como objetivo analisar a produção de artigos científicos que abordam a temática Educação do Campo em quatro revistas nacionais, a saber: Revista Educação \& Formação, Revista Exitus, 
Revista Práxis Educacional e Revista Tempos e Espaços em Educação. Assim, buscamos compreender como estão sistematizadas as discussões acerca das políticas educacionais para o campo, e as contradições subjacentes entre a construção da categoria Educação do Campo em contraposição à Educação Rural. Para isso, foram investigados artigos publicados nos últimos cinco anos, nos arquivos do site oficial de cada uma das revistas mencionadas.

O recorte temporal para a seleção dos artigos publicados levou em consideração tão somente o período entre os meses de janeiro de 2015 a maio de 2020, com o objetivo de abranger o maior número de publicações possíveis levando em consideração a temática da Educação do Campo. Para a classificação dos trabalhos e análise foram consideradas palavraschave que pudessem fazer relação com a temática pesquisada acrescidas de outras, quais sejam: Educação Rural; Escola do campo; Escola rural; Campo; Camponeses; Escola agrícola. Foram encontrados um total de 41 publicações divididas entre as quatro revistas, com destaque para a Revista Práxis Educacional, que em 2017 publicou um dossiê temático sobre a Educação do Campo em perspectiva Latino-americana.

Desse modo, pretendemos com esta pesquisa, além de analisar as produções dos últimos anos, possibilitar um aporte significativo para se pensar os apontamentos que foram trazidos por estes autores, e também, identificar lacunas nas produções de uma temática tão relevante e atual. É importante a produção científica nesta área, pois além de valorizar as conquistas é preciso investigar a prática, a efetivação das políticas públicas educacionais adquiridas nos processos de luta pelos movimentos sociais e sujeitos coletivos do campo. O trabalho está organizado da seguinte forma: no primeiro momento apresentaremos um resgate histórico da Educação do Campo no Brasil e suas políticas públicas, posteriormente é realizada a análise do levantamento das publicações. Por fim, algumas considerações sobre os artigos encontrados.

\section{A EDUCAÇÃO DO CAMPO NO BRASIL}


Os debates acerca da Educação do Campo não são recentes, sua visibilidade e conquistas são oriundos dos movimentos sociais do campo. A Educação do Campo nasce das lutas da classe trabalhadora camponesa organizada "[...] principalmente, como movimentos sociais que buscam um projeto educacional na forma de política pública, e que respeite os interesses dos diversos sujeitos coletivos que fazem do campo o seu território de vida" (SANTOS, 2017). Na última década, os movimentos sociais conquistaram algumas políticas públicas educacionais que sustentam a Educação do Campo no país, políticas que devem ser valorizadas, debatidas e pesquisadas em sua prática, buscando sempre avanços para efetivação de uma educação de qualidade.

Nesse contexto, de acordo com Ferreira e Brandão (2011), os primeiros debates sobre a educação do campo foram realizados no "I Encontro Nacional de Educadoras e Educadores da Reforma Agrária" (ENERA), promovido pelo Movimento Sem Terra(MST), com o apoio da Organização das Nações Unidas para Educação, Ciência e Cultura (UNESCO), Fundo das Nações Unidas para a Infância (UNICEF); Conferência Nacional dos Bispos do Brasil (CNBB); Universidade de Brasília (UnB), em 1997, e, posteriormente, também na intitulada "I Conferência Nacional por uma Educação Básica do Campo", realizada em Luziânia/GO, onde os conferencistas elaboraram propostas de políticas públicas para a Educação do Campo no Brasil.

Roseli Caldart, uma das autoras mais citadas nos textos publicados dos periódicos investigados, analisa que em um contexto de lutas, pensado pelos movimentos sociais,

A educação do campo toma posição, age, desde uma particularidade e não abandona a perspectiva da universalidade, mas disputa sua inclusão nela. [...] a Educação do Campo tem se centrado na escola e luta para que a concepção de educação que oriente suas práticas se descentre da escola, não fique refém da sua lógica constitutiva, exatamente para poder ir bem além dela enquanto projeto educativo. [...] se coloca em luta pelo acesso dos trabalhadores ao conhecimento produzido na sociedade e ao mesmo tempo problematiza, faz crítica ao modo de conhecimento dominante [...] (CALDART, 2009, p.38). 
A Educação do Campo tem em sua gênese a luta contra as injustiças sociais sofridas pelo sujeito do campo. Luta pelo acesso à escola no meio rural, mas não uma escola no modelo capitalista que desvaloriza a agricultura familiar e os camponeses, ao contrário, uma escola que reconheça o homem do campo e sua importância social. Nesse sentido, está ligada ao contexto social do campo, bem como as histórias dos sujeitos e suas lutas, como afirmam Fonseca e Krause (2018, p.2), em um dos artigos encontrados nas publicações de 2018: "[...] é considerar que a Educação do Campo ocorre imbricada pelo contexto, pelos sujeitos, pelas histórias de vida e de luta".

No contexto social da atualidade, pré-determinado pelo modelo capitalista que tem como objetivo a acumulação e o lucro, a educação para os sujeitos do campo é pensada visando os interesses do capital, de expropriação da terra para o agronegócio e qualificação de mão de obra barata. Assim, existem dois modelos de educação para as áreas rurais: a Educação do campo e a educação rural. No que concerne a diferença entre ambos, coadunamos com as proposições de Juenqueira e Bezerra (2015, p.12),

[..] ao atribuir a educação rural um papel ideológico importante na saída do homem do campo, pela lógica a educação do campo cumpriria um papel de manter o homem no campo. Na visão do Movimento, a educação do campo distingue-se da educação rural, por não fundar-se em políticas impostas aos sujeitos do campo, mas construída por eles e com eles.

A Educação do Campo se contrapõe a Educação Rural, uma vez que, tem como objetivo a valorização do homem do campo. O modelo de Educação Rural que predominou e ainda predomina no país, não é pensada pelos sujeitos a quem é destinada a educação, tem objetivo de formar mão de obra barata para o mercado de trabalho, e retrata o campo a partir do olhar capitalista estereotipado, inferiorizado. As características de cada projeto educativo e suas discrepâncias são apresentados no quadro abaixo. 
Quadro 1: Educação Rural e Educação do campo: características e convergências

\begin{tabular}{|c|c|}
\hline Educação Rural & Educação do Campo \\
\hline $\begin{array}{c}\text { Definida a partir dos objetivos do mercado } \\
\text { de trabalho; }\end{array}$ & Construída pelos povos do campo; \\
\hline $\begin{array}{c}\text { Retrata o campo em um olhar capitalista, } \\
\text { vendo os sujeitos de forma inferiorizada; }\end{array}$ & $\begin{array}{c}\text { Valorização do homem do campo, da } \\
\text { formação humana enquanto direito; }\end{array}$ \\
\hline Pensada a partir do mundo urbano & $\begin{array}{c}\text { Pensada a partir da realidade do sujeito, } \\
\text { valorizando sua cultura e relação com a } \\
\text { terra. }\end{array}$ \\
\hline
\end{tabular}

Fonte: Elaborado pelas autoras (2020).

Nesse contexto, a Educação do Campo representa um projeto educativo contrário ao modelo proposto pela sociedade capitalista atual, que exclui e inferioriza o homem do campo. Assim, se constitui sua origem e militância, "[...] a educação do campo nasceu da problemática da exclusão provocada pelo sistema capitalista que atinge a população camponesa, e esta, por sua vez, articula-se em uma relação direta com os diferentes processos de luta social, desenvolvida pelos movimentos sociais e sindicais" (FREITAS; SOUZA, 2015, p.6).

Uma educação idealizada verticalmente para o sujeito do campo não é uma educação do campo, mas, uma Educação "no" Campo, pois como afirma Caldart (2009, p.41): "Na sua origem o "do" da Educação do Campo tem a ver com esse protagonismo: não é 'para' nem mesmo 'com': é dos trabalhadores, educação do campo, dos camponeses, pedagogia do oprimido [...]".

Assim, na Educação do Campo a luta é por espaço, fazendo emergir algumas indagações à sociedade, como por exemplo:

De que forma são asseguradas às crianças e aos jovens da zona rural uma educação de qualidade? Qual o projeto de desenvolvimento econômico para o rural? Como tratar o rural não como resíduo do urbano? De que forma pode haver a cooperação entre o campo e a cidade? Uma coisa é certa, o que tem que ser buscado não é deter o homem no campo, mas o caminho inverso, ou seja, promover as políticas públicas nas áreas rurais e nas pequenas cidades, levar as políticas de investimento onde de fato precisam, como: educação, saúde, habitação, saneamento, emprego, previdência, crédito, lazer, ou seja, políticas contra a expropriação do homem do campo[...] (NUNES; NETO, 2016, p.4). 
Portanto, a concepção de uma escola e uma educação do campo transforma um paradigma de educação para esses sujeitos, antes invisibilizados. O "do" campo, concebe um modelo de educação construída pelos próprios sujeitos da educação, ou seja, uma escola para o povo camponês pensada e articulada por esse mesmo povo, reconhecendo seus saberes, suas problemáticas, suas necessidades, sua cultura. Cabe agora, a parir dessas concepções, pensar e lutar por políticas públicas educacionais que efetivem esses ideais.

\section{Políticas públicas educacionais para a Educação do Campo}

Em virtude da crescente luta e cobrança dos povos do campo por uma Educação que respeitasse e reconhecesse suas especificidades, foram conquistadas as políticas públicas educacionais para responder a tais reivindicações. Desse modo, as políticas públicas, segundo Santos e Carvalho (2019, p. 4), "podem ser definidas como um elenco característico de ações promovidas pelos atores governamentais, com objetivos de produzirem resultados específicos em diversas áreas na arena social, educacional, saúde, cultura, etc.".

Destarte, existem no cenário nacional, políticas públicas educacionais destinadas aos povos do campo e/ou os contempla, em sua maioria, conquistadas a partir das reivindicações e enfrentamentos ao Estado capitalista. Destacamos no quadro abaixo algumas destas políticas, também denominadas de marcos políticos e legais.

Quadro 2: Marcos políticos e legais da Educação do Campo no Brasil

\begin{tabular}{|c|c|c|}
\hline Marcos políticos e legais & Ano de criação & Descrição \\
\hline Lei $n^{\circ} 9.394 / 96$, Art. 23 e 28 & 1996 & $\begin{array}{l}\text { Lei de Diretrizes e Bases da } \\
\text { Educação (LDB) }\end{array}$ \\
\hline Lei $n^{\circ} 9.424 / 9$, Art. $1^{\circ}$ & 1996 & $\begin{array}{l}\text { Dispõe sobre o Fundo de } \\
\text { Manutenção }\end{array}$ \\
\hline
\end{tabular}




\begin{tabular}{|c|c|c|}
\hline & & $\begin{array}{llr}\text { Desenvolvimento } & \text { do } & \text { Ensino } \\
\text { Fundamental } & \text { e de } \\
\text { Valorização do } & \text { Magistério } \\
\text { (FUNDEF) } & \end{array}$ \\
\hline Resolução CNE/CEB n ${ }^{\circ} 1$ & Abril de 2002 & $\begin{array}{l}\text { Institui as } \\
\text { Operacionais da Educação } \\
\text { Básica para as Escolas do } \\
\text { Campo }\end{array}$ \\
\hline Lei n 10.880 & Junho de 2004 & $\begin{array}{l}\text { Institui o Programa Nacional } \\
\text { de Apoio ao Transporte do } \\
\text { Escolar - PNATE }\end{array}$ \\
\hline Parecer CNE/CEB nº 01/2006 & 2006 & $\begin{array}{l}\text { Reconhece a aplicação da } \\
\text { Pedagogia de Alternância } \\
\text { nos Centros Familiares de } \\
\text { Formação por Alternância } \\
\text { (CEFFA) }\end{array}$ \\
\hline Decreto $n^{\circ} 6.040$ & Fevereiro de 2007 & $\begin{array}{l}\text { Institui a Política Nacional de } \\
\text { Desenvolvimento Sustentável } \\
\text { dos Povos e Comunidades } \\
\text { Tradicionais (PNPCT) }\end{array}$ \\
\hline Procampo & 2007 & $\begin{array}{l}\text { Criação do Programa de } \\
\text { Apoio à Formação Superior } \\
\text { em Licenciatura } \\
\text { Educação do em } \\
\text { PROCAMPO }\end{array}$ \\
\hline Resolução CNE/CEB n 2 & Abril de 2008 & $\begin{array}{l}\text { Estabelece as Diretrizes } \\
\text { Operacionais da Educação } \\
\text { Básica para as Escolas do } \\
\text { Campo (complementares) }\end{array}$ \\
\hline Resolução/CD/FNDE n 45 & Agosto de 2009 & $\begin{array}{l}\text { Estabelece os critérios e } \\
\text { procedimentos para a } \\
\text { transferência automática de } \\
\text { recursos financeiros do } \\
\text { Programa ProJovem Campo } \\
\text { - Saberes da Terra aos } \\
\text { Estados }\end{array}$ \\
\hline Decreto $n^{\circ} 7.352 / 2010$ & Novembro de 2010 & $\begin{array}{l}\text { A política de educação do } \\
\text { campo e o PRONERA }\end{array}$ \\
\hline Resolução/CD/FNDE n² 26 & Setembro de 2010 & $\begin{array}{l}\text { Estabelece orientações e } \\
\text { diretrizes para a transferência } \\
\text { de recursos financeiros às } \\
\text { Instituições de Ensino superior } \\
\text { no âmbito do Programa } \\
\text { Escola Ativa }\end{array}$ \\
\hline Lei $n^{\circ} 12.695$, Art. $1^{\circ}$ & Julho de 2012 & $\begin{array}{l}\text { [...] Contempla com recursos } \\
\text { do FUNDEB as instituições } \\
\text { comunitárias que atuam na } \\
\text { educação do campo[..] }\end{array}$ \\
\hline Resolução n³6 & Agosto de 2012 & $\begin{array}{l}\text { PDDE Campo - Programa } \\
\text { Dinheiro Direto na Escola }\end{array}$ \\
\hline Resolução n³2 & Agosto de 2012 & PDDE Água na Escola \\
\hline Resolução n $8\left(\right.$ Art. $\left.^{\circ}{ }^{\circ}\right)$ & $\begin{array}{l}20 \text { de novembro de } \\
2012\end{array}$ & $\begin{array}{l}\text { Diretrizes Curriculares } \\
\text { Nacionais para a Educação } \\
\text { Escolar Quilombola na } \\
\text { Educação Básica }\end{array}$ \\
\hline
\end{tabular}




\begin{tabular}{|c|c|c|}
\hline Resolução/CD/FNDE n 18 & Maio de 2013 & $\begin{array}{l}\text { Dispõe sobre a destinação } \\
\text { de recursos financeiros, nos } \\
\text { moldes operacionais e } \\
\text { regulamentares do Programa } \\
\text { Dinheiro Direto na Escola } \\
\text { (PDDE), [...]a fim de } \\
\text { favorecer a melhoria da } \\
\text { qualidade de ensino e a } \\
\text { promoção } \\
\text { sustentabilidade } \\
\text { socioambiental nas unidades } \\
\text { escolares }\end{array}$ \\
\hline Portaria n $86 / 2013$ & 2013 & $\begin{array}{lrr}\text { PORTARIA } & N^{\circ} \text { 86/2013, que } \\
\text { institui O PRONACAMPO- } \\
\text { Programa Nacional de } \\
\text { Educação do Campo }\end{array}$ \\
\hline Portaria $n^{\circ} 674$ & Agosto de 2013 & $\begin{array}{l}\text { PORTARIA } N^{\circ} \text { 674- } \text { Institui a } \\
\text { Comissão Nacional de } \\
\text { Educação do campo, órgão } \\
\text { colegiado de caráter } \\
\text { consultivo, com atribuição } \\
\text { de assessorar o Ministério da } \\
\text { Educação na formulação de } \\
\text { políticas para a Educação } \\
\text { do Campo }\end{array}$ \\
\hline Resolução $n^{\circ} 38\left(\right.$ Art. $\left.1^{\circ}\right)$ & Outubro de 2013 & $\begin{array}{l}\text { Estabelece orientações e } \\
\text { procedimentos para o } \\
\text { pagamento de bolsas de } \\
\text { estudo e pesquisa no âmbito } \\
\text { da Escola da Terra }\end{array}$ \\
\hline $\begin{array}{l}\text { Lei } n^{\circ} 9394 / 96, \text { modificado o Art. } 28 \text {, } \\
\text { pela Lei } n^{\circ} 12.960\end{array}$ & $\begin{array}{l}\text { Modificação em } \\
\text { março de } 2014\end{array}$ & $\begin{array}{l}\text { O fechamento das escolas } \\
\text { do campo }\end{array}$ \\
\hline Portaria $n^{\circ} 505$ & Maio de 2015 & $\begin{array}{l}\text { Cria a Comissão Nacional de } \\
\text { Educação Profissional e } \\
\text { Tecnológica do Campo nas } \\
\text { Redes Públicas- CNEPT }\end{array}$ \\
\hline
\end{tabular}

Fonte: Elaborado pelas autoras (2020).

Essas políticas foram, em sua maioria, contempladas nos estudos encontrados pela pesquisa, principalmente as mais recentes. Como por exemplo, o artigo "A quem interessa a educação dos trabalhadores do campo? Uma análise do Pronacampo", de Junqueira e Bezerra (2015), que analisa o Pronacampo, política instituída no ano de 2013 como aponta o quadro. Bem como, estudos sobre o Pronera, como "Educação do Campo e desafios amazônicos: o Pronera no Estado do Amapá" de Costa e Lomba (2017), que analisa o processo de materialização do programa e a sua relevância aos trabalhadores dos assentamentos da Reforma Agrária no Estado do Amapá. Também, estudos relacionados ao fechamento das 
escolas do campo, como "A Política de Fechamento de Escolas no Campo na Região Metropolitana de Curitiba/PR" de Pereira e Souza (2017).

As políticas públicas educacionais que abrangem a Educação do Campo, bem como seu contexto histórico e possíveis entraves, são objeto de estudo de algumas das publicações encontradas, como por exemplo, o artigo de Freitas e Souza (2015) "Estado, Política e Educação do Campo: uma revisão de conceitos á luz da Pedagogia Histórico Crítica". Além disso, produções que analisam a relação entre campo e cidade, suas contradições, interesses, cabe destacar: "Urbano e rural: contradições e influências no (re) pensar da ruralidade no Brasil" (NUNES; NETO, 2016), também "Ruralidade e sociedade em rede" (SAMBORSKI, 2016).

Assim, as políticas públicas, anteriormente citadas, apontam para a Educação do Campo enquanto direito dos camponeses e dever do Estado, que é garantido por lei desde a educação básica à formação de professores para atuarem nas escolas do campo. Portanto, é preciso realizar discussões com o intuito de analisar a implementação destas políticas, bem como pensar avanços a partir do que já foi conquistado, visto que o campo "[...] é lugar de vida e, sobretudo, de educação" (FERNANDES, 2008, p. 137).

\section{Estado da Arte das produções de artigos sobre Educação do Campo nas revistas pesquisadas}

Com o objetivo de analisar a produção de artigos científicos que abordam a temática Educação do Campo em quatro revistas nacionais, foi realizado o estado da arte devido a necessidade de fazer um mapeamento das produções nos últimos cinco anos. A pesquisa denominada "estado da arte" tem como objetivo, segundo Romanowski e Ens (2006, p.39), "compreender como se dá a produção científica em uma determinada área de conhecimento em teses de doutorado, dissertações de mestrado, artigos de periódicos e publicações".

No contexto desta pesquisa, o estado da arte foi realizado em artigos publicados em revistas, tendo como temática buscada a Educação do Campo, sustentados e movidos pelo desafio de conhecer o que já tem 
produzido e dedicar cada vez mais atenção as pesquisas realizadas (FERREIRA, 2002), bem como suas problemáticas e achados, evidenciando a quantidade de publicações por ano e por revista.

Para a elaboração do levantamento dos artigos publicados na Revista Educação \& Formação, Revista Exitus, Revista Práxis Educacional e Revista Tempos e Espaços em Educação, foram utilizados como base de dados os sites oficiais destas e seus respectivos arquivos de edições desde janeiro de 2015 a maio de 2020. Consideramos as seguintes palavras-chave: Educação do Campo; Educação Rural; Escola do campo; Escola rural; Campo; Camponeses; Escola agrícola. Cabe destacar que a Revista Educação \& Formação tem publicações a partir de 2016, quando foi lançado seu primeiro volume e, consequentemente, sua primeira edição. Nas quatro revistas foi encontrado um total de 41 publicações, sendo distribuídas segundo o gráfico 1 .

Gráfico 1: Publicações de artigos sobre Educação do Campo (2015-2020)

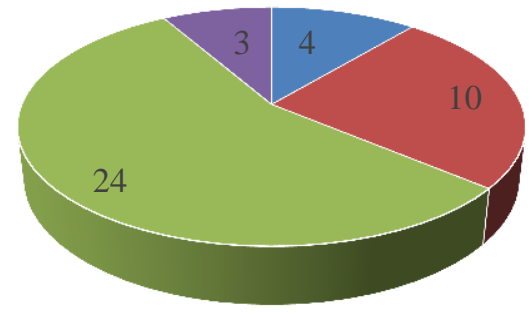

- Educação \& Formação

- Práxis Educacional
- Exitus

- Tempos e Espaços em Educação

Fonte: Elaborado pelas autoras, 2020.

Neste contexto, é possível analisar que a revista que possui mais publicações que abarcam a temática em estudo é a Revista Práxis Educacional, com 24 artigos, seguida pela Revista Exitus com dez textos. Apesar de ter iniciado suas publicações em 2016, a Revista Educação \& Formação possui quatro artigos que tratam da temática investigada. $\mathrm{O}$ ano 
que teve o maior número de trabalhos publicados nas três revistas foi 2017 , seguido por 2019, como apontado no quadro abaixo.

Gráfico 2: Quantidade de artigos publicados nos últimos cinco anos sobre a Educação do campo nas revistas pesquisadas

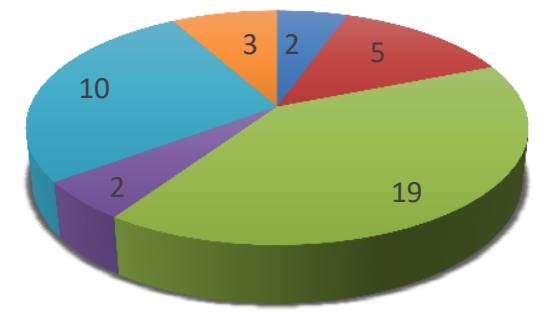

[ $2015 \square 2016 \square 2017 \quad 2018 \square 2019 \square 2020$

Fonte: Elaborado pelas autoras, 2020.

As publicações aconteceram em maior número em 2017, com 19 artigos que tratam da temática Educação do Campo. Os anos de 2018 e 2015 chama a atenção pela pouca quantidade de publicações se comparado com outros momentos, ademais o ano de 2020 foi analisado até o mês de maio, e ainda assim, aparece como três publicações. É importante destacar também, que a Revista Práxis Educacional publicou em 2017 o dossiê temático intitulado "Educação do Campo em Perspectiva Latino Americana" onde foram encontrados doze artigos que abrangem as palavras-chave pesquisadas, como demonstra o quadro 3.

Quadro 3: Artigos publicados no dossiê temático intitulado "Educação do Campo em Perspectiva Latino Americana" pela Revista Práxis Educacional em 2017

\begin{tabular}{|l|l|}
\hline \multicolumn{1}{|c|}{ Título do artigo } & \multicolumn{1}{|c|}{ Autores } \\
\hline $\begin{array}{l}\text { Movimentos Sociais e Educação do Campo na } \\
\text { América Latina: Aprendizagens de um percurso } \\
\text { histórico }\end{array}$ & Lia Pinheiro Barbosa, Peter Michael Rosset \\
\hline $\begin{array}{l}\text { Os impactos do PAR nos municípios de Vitória } \\
\text { da Conquista, llhéus e ltabuna (2013-2017) }\end{array}$ & $\begin{array}{l}\text { Arlete Ramos dos Santos, Elisângela Andrade } \\
\text { Moreira Cardoso, Niltânia Brito Oliveira }\end{array}$ \\
\hline Crítica à crítica ao paradigma da educação & Rodrigo Simão Camacho, Bernardo Mançano \\
\hline
\end{tabular}

Revista Exitus, Santarém/PA, Vol. 10, p. 01-25, e020062, 2020. 


\begin{tabular}{|c|c|}
\hline do campo & Fernandes \\
\hline $\begin{array}{l}\text { Agroecologia e práticas pedagógicas na } \\
\text { educação do campo }\end{array}$ & Silvana Lúcia da Silva Lima \\
\hline $\begin{array}{l}\text { A política de fechamento de escolas no } \\
\text { campo na região metropolitana de Curitiba/PR }\end{array}$ & $\begin{array}{l}\text { Camila Casteliano Pereira, Maria Antônia de } \\
\text { Souza }\end{array}$ \\
\hline $\begin{array}{l}\text { O jeito CPT de fazer formação- a comissão } \\
\text { pastoral da terra ensina e aprende com } \\
\text { trabalhadores rurais }\end{array}$ & Amone Inacia Alves \\
\hline $\begin{array}{l}\text { Um olhar sobre a formação de educadores: o } \\
\text { fazer pensar da utopia }\end{array}$ & Adelar João Pizetta \\
\hline $\begin{array}{l}\text { Pedagogia da alternância e prática educativa } \\
\text { na educação do campo: experiência da } \\
\text { Escola família agrícola Dom Fragoso no Ceará }\end{array}$ & $\begin{array}{l}\text { Regina Coele Queiroz Fraga, Jose Ribamar } \\
\text { Furtado de Sousa }\end{array}$ \\
\hline $\begin{array}{l}\text { "Chama a roda" na escola família agrícola de } \\
\text { Santa Cruz do Sul: o círculo de cultura } \\
\text { reinventado na pedagogia da } \\
\text { Alternância }\end{array}$ & $\begin{array}{l}\text { Cheron Zanini Moretti, Cristina Luisa Bencke } \\
\text { Vergutz, João Paulo Reis Costa }\end{array}$ \\
\hline $\begin{array}{l}\text { Construyendo Pedagogías emancipatórias: la } \\
\text { escuela campesina de agroecología-mendoza, } \\
\text { argentina }\end{array}$ & Rocío Peterle, Marta Lía Greco, Facundo Martín \\
\hline $\begin{array}{l}\text { Por uma Escola Infantil com Biblioteca: dos } \\
\text { fundamentos aos apontamentos de práticas }\end{array}$ & Marcos Gehrke \\
\hline $\begin{array}{llll}\text { Os Mediadores Pedagógicos e e } & \text { a } \\
\text { Territorialização da Agroecologia } & & \\
\end{array}$ & Nils McCune \\
\hline
\end{tabular}

Fonte: Elaborado pelas autoras, 2020.

Os artigos que compõe o dossiê temático "Educação do Campo em Perspectiva Latino Americana" trazem diversos apontamentos, em destaque para pesquisas relacionadas à práticas educativas no campo. O artigo "O Jeito CPT de Fazer Formação - a Comissão Pastoral da Terra ensina e aprende com trabalhadores rurais", fruto da pesquisa de doutorado de Alves (2017), que teve como objetivo mapear as experiências educativas da educação não-formal realizada com trabalhadores rurais no estado, formados pela Comissão Pastoral da Terra (CPT) e também a fim de compreender como se davam os cursos de formação e como a CPT entendia esse processo. Assim, as experiências educativas dos trabalhadores rurais tiveram espaço nos estudos, como trata também o estudo "Pedagogia da alternância e prática educativa na educação do campo: experiência da escola família agrícola Dom Fragoso no Ceará", de Fraga e Souza (2017), além da pesquisa "Chama a roda" na escola família agrícola de Santa Cruz do Sul: o círculo de cultura reinventado na pedagogia da alternância", de autoria de Moretti, Vergutz e Costa (2017). Desse modo, os artigos abordam 
práticas pedagógicas com camponeses e seus filhos em Escolas Famílias Agrícolas salientando outras pedagogias, como a Pedagogia da Alternância como modo de educação do/no campo.

Na Pedagogia da Alternância regulamentada por meio do Parecer CNE/CEB n. 01/2006, difundida pelas Casas Familiares Rurais (CFRs) e pelas Escolas Famílias Agrícolas (EFAs), há uma valorização dos saberes construídos nas práticas sociais, principalmente a experiência do trabalho. Realiza-se em tempos e espaços que se alternam entre escola e propriedade, comunidade, assentamento, acampamento ou movimento social ao qual o educando está vinculado (RIBEIRO, 2008). Tem se mostrado um movimento de diálogo com a prática dos sujeitos, valorizando seu espaço e saberes, como reafirmam Fraga e Souza: "A possibilidade do diálogo produzido pela Pedagogia da Alternância, de modo especial, na dinâmica das famílias que constituem as comunidades, é gérmen prático no saber cotidiano e merecem atenção de educadores e educadoras [...]" (2017, p.17).

Os movimentos sociais também têm espaço nos artigos publicados no dossiê, como exemplo, o estudo intitulado "Movimentos Sociais e Educação do Campo na América Latina: aprendizagens de um percurso histórico", de Barbosa e Rosset (2017). O referido artigo destaca que o projeto educativopolítico da Educação do Campo ultrapassou as fronteiras locais e nacionais, estabelecendo pontes de diálogo e aprendizagens com outras organizações e movimentos sociais do campo na América Latina, ganhando, assim, maior visibilidade. Enfatiza também o papel da Educação do Campo na consolidação de um Paradigma Epistêmico do Campo e de uma Pedagogia Camponesa Agroecológica, que além de valorizar os camponeses, defende a produção de alimentos saudáveis. A pesquisa reafirma a importância dos movimentos sociais para a conquista de direitos para os camponeses, apontando o Movimento Sem Terra (MST) como protagonista nesse processo de luta, que compreende desde a educação à reforma agrária.

Neste contexto, os movimentos sociais emergem, no Brasil, em um contexto histórico de uma origem colonial, escravocrata, de exploração e 
pilhagem, além das relações sociais serem alicerçadas em um antagonismo de classes que sustentam o modelo de sociedade vigente:

Tampouco podemos omitir, ou mesmo minimizar, o peso simbólicoideológico e as implicações socioculturais, políticas e jurídicas dos 380 anos do regime escravocrata brasileiro na constituição do Estado-nação no Brasil, bem como no antagonismo de classe que se incrusta, em definitiva, na contradição campo-cidade (BARBOSA; ROSSET, 2017, p.9).

Acerca dos movimentos sociais no campo destaca-se o MST, que se constituiu como um movimento social articuladamente organizado que luta pela reforma agrária, cria cooperativas de produção e comercialização, funda escolas de formação para as lideranças, discute/organiza/desenvolve o tipo de educação que a eles deve ser destinado (GOHN, 1997). Em sua defesa pela terra e um projeto de educação que os valorize e represente, ganhou visibilidade internacional e foi importante na conquista de políticas públicas para a Educação do Campo. Por isso, os estudos sobre os movimentos sociais são necessários, devido a sua importância na luta por direitos e nas organizações de suas práticas educativas.

Acredita-se ser importante destacar o artigo intitulado "A política de fechamento de escolas no campo na região metropolitana de Curitiba/PR", produzido por Pereira e Souza (2017). O estudo problematiza a efetivação de poíticas públicas educacionais destinadas ao estudante do campo, como o transporte escolar e evidencia a prática de nucleação de escolas, como determinantes para o processo do fechamento de escolas. Após realizar a pesquisa em escolas localizadas no campo na Região Metropolitana de Curitiba (RMC), as autoras concluíram que a política de fechamento de escolas é mais um dos arranjos do capitalismo agrário que contribui para os processos de migração do campo para a cidade, se fazendo necessário assim o enfrentamento dessa realidade de negação de direitos.

Posteriormente, analisando as publicações de artigos nos últimos cinco anos, 2015 e 2018 chamam a atenção, devido a publicação de apenas dois artigos que abrangem a temática Educação do Campo em cada ano; em 2015, ambos pela Revista Exitus, já em 2018, um foi publicado pela Revista 
Educação \& Formação outro pela Revista Práxis Educacional. Os dois artigos do ano de 2015, da Revista Exitus, abordam respectivamente questões relacionadas ao Pronacampo (JUNQUEIRA; BEZERRA, 2015) e um estudo da relação entre Estado, política e educação do campo a partir da pedagogia histórico-crítica (FREITAS; SOUZA, 2015). Em 2018, o artigo da revista Educação \& Formação abordou contribuições acerca da relação entre ciências da natureza e Educação do Campo (FONSECA; BIERHALZ, 2018), bem como, houve também a publicação de uma pesquisa que aborda a história de professores iniciantes na zona rural (FERREIRA; ANUNCIATO, 2018) na revista Práxis Educacional, em seu dossiê Temático: Formação e Prática Pedagógica.

Em 2019, foram publicados dez artigos que se relacionam com a Educação do Campo, pelas Revista Exitus, Práxis Educacional e Tempos e Espaços em Educação. O maior número de artigos foi publicado pela Práxis Educacional, com quatro estudos, seguida de Tempos e Espaços em Educação e pela Revista Exitus, com três textos em cada, como demonstra o gráfico abaixo:

Gráfico 3: Artigos publicados no ano de 2019 pelas revistas: Exitus, Práxis Educacional e Tempos e Espaços em Educação que abrangem a Educação do Campo

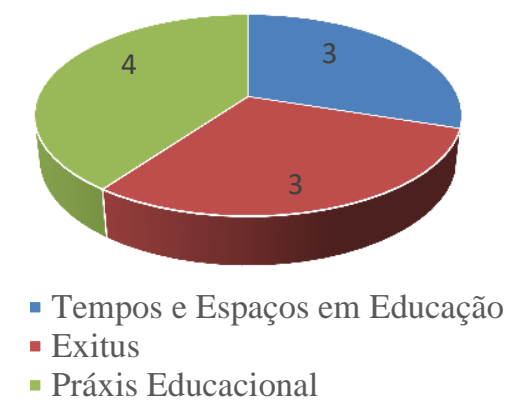

Fonte: Elaborado pelas autoras, 2020.

As dez publicações encontradas abordam diferentes questões relacionadas a Educação do Campo. Os artigos da Revista Tempos e Espaços em Educação contribuem com apontamentos acerca da agroecologia e dos programas Pronacampo e Pronera, assim, com destaque de estudos sobre a implementação das políticas públicas da Educação do Campo. Ademais, os estudos encontrados na Revista Exitus 
abordam práticas educativas no campo como trajetórias de sucesso, experiência de audição radiofônica em uma comunidade rural e utilização de histórias em quadrinhos com jovens e adultos camponeses. Em suma, as pesquisas nesta última, abrangem práticas pedagógicas no campo, enquanto as publicações da primeira compreendem estudos sobre as políticas públicas e sua implementação no campo, se constituindo assim, com temas diversos e relevantes.

Já a Revista Práxis Educacional, se destaca com maior quantidade de publicações (quatro) no ano de 2019, sendo constituída de pesquisas que analisam, em sua maioria, práticas pedagógicas no campo. A saber, alguns dos artigos encontrados foram: "Educação integral de tempo integral: diagnóstico da implantação em escola do campo" de Vasconcelos et al. (2019) e "Percepções docentes sobre práticas de letramento literário nos anos iniciais em uma escola do campo", elaborado por Rodrigues et al. (2019). Cabe destacar o artigo "Educando com o livro e a enxada": Robert King Hall e o programa de educação rural do INEP (1949-1951)", de Cunha e Maynard (2019), o qual analisa a colaboração do pesquisador estadunidense Robert King Hall junto ao programa de educação rural, coordenado pelo Instituto Nacional de Estudos Pedagógicos (INEP) na década de 1940, no Brasil, apontando que Hall realizou uma análise crítica, indicando mudanças importantes a serem realizadas no projeto.

Nesse contexto, acredita-se ser importante destacar 0 artigo publicado pela Revista Tempos e Espaços em Educação, "MST, agroecologia e educação do campo na Amazônia: um estudo sob o enfoque das Epistemologias do Sul", de Corrêa e Nascimento (2019). O estudo analisa a agroecologia e Educação do Campo no MST, no âmbito dos assentamentos rurais na Amazônia, enfatizando a importância desse movimento nas reivindicações por políticas públicas, bem como seus avanços e contradições. Evidenciou-se que as discussões sobre a Educação do Campo são homogêneas e inacabadas, em uma conjuntura de luta de classes, em que a própria pesquisa se torna sinal de resistência. 
Nesses termos, a proposta de educação do campo se insere nessa discussão e está longe de ser compreendida como acabada, homogênea e harmônica. Ela está em movimento e sendo tencionada por esse próprio movimento de contradições e conflitos, que não pode prescindir da categoria de lutas de classes, contudo não pode se reduzir a ela, correndo o risco de invisibilizar outras dinâmicas de dominação e resistência (CORRÊA; NASCIMENTO, 2019, p. 21).

Em 2020, apesar de serem analisadas publicações até o mês de maio, foram encontrados três artigos, divididos entre a Revista Educação \& Formação, Revista Exitus e a Revista Práxis Educacional, como mostra o quadro abaixo:

Quadro 4: Artigos que tratam da temática Educação do Campo publicados em 2020, pelas revistas: Educação \& Formação, Exitus e Práxis Educacional

\begin{tabular}{|c|c|c|}
\hline & Artigos & Autores \\
\hline $\begin{array}{l}\text { Revista Educação \& } \\
\text { Formação }\end{array}$ & $\begin{array}{l}\text { O jogo em turmas } \\
\text { multisseriadas de escolas } \\
\text { rurais: auxílio à adoção de } \\
\text { regras essenciais à vida }\end{array}$ & $\begin{array}{c}\text { SILVA, Nilvania Dos Santos; } \\
\text { SILVA, Joana D`arc Fontes } \\
\text { Azevedo; COSTA, Ruth } \\
\text { Tomaz da. }\end{array}$ \\
\hline Revista Exitus & $\begin{array}{l}\text { Jovens do campo no } \\
\text { ensino superior }\end{array}$ & $\begin{array}{c}\text { NASCIMENTO, Mirian } \\
\text { Bezerra de Matos; } \\
\text { MARQUES, Tatyanne } \\
\text { Gomes; TRINDADE, } \\
\text { Domingos Rodrigues da. }\end{array}$ \\
\hline Revista Práxis Educacional & $\begin{array}{l}\text { Os pontos convergentes } \\
\text { entre os/as teóricos/as da } \\
\text { educação do campo }\end{array}$ & $\begin{array}{l}\text { BORGES, Heloisa da Silva; } \\
\text { OLIVEIRA, Bianca da Silva. }\end{array}$ \\
\hline
\end{tabular}

Fonte: Elaborado pelas autoras, 2020.

O artigo publicado pela Revista Educação \& Formação aborda a utilização de jogos em turmas multisseriadas no campo e suas contribuições para aprendizagens de regras de convivência em sociedade. A pesquisa "Jovens do campo no ensino superior", da Revista Exitus, chama a atenção para uma temática até então não encontrada nos estudos, analisando a trajetória de vida de jovens camponeses no ensino superior, uma pesquisa realizada na Universidade do Estado da Bahia (UNEB), mais especificamente no Campus XII- Guanambi. Em seguida, conforme apresentado no quadro 4, o texto publicado pela Revista Práxis Educacional, "Os pontos convergentes entre os/as teóricos/as da educação do campo", que centrou os estudos na 
temática da Educação do Campo e sua relação com a perspectiva dos Movimentos Sociais do Campo, considerando suas contribuições para a formulação de uma educação significativa e contextualizada para os sujeitos desse contexto.

Em suma, ao analisar as publicações dos últimos cinco anos, foram encontradas diversas pesquisas que trazem inúmeras contribuições para a Educação do Campo. Logo, se faz importante identificar a quantidade de estudos publicados por revista em cada ano analisado, como apontado no quadro a seguir.

Quadro 5: Publicações de artigos sobre a Educação do Campo por ano (20152020), pelas revistas pesquisadas

\begin{tabular}{|c|c|c|c|c|}
\hline Ano & $\begin{array}{c}\text { Revista } \\
\text { Educação \& } \\
\text { Formação }\end{array}$ & Revista Exitus & $\begin{array}{c}\text { Revista Práxis } \\
\text { Educacional }\end{array}$ & $\begin{array}{c}\text { Revista } \\
\text { Tempos e } \\
\text { Espaços em } \\
\text { Educação }\end{array}$ \\
\hline 2015 & 0 & 2 & 0 & 0 \\
\hline 2016 & 2 & 2 & 3 & 0 \\
\hline 2017 & 1 & 0 & $\begin{array}{c}15 \\
\text { Dossiê temático } \\
(12)\end{array}$ & 0 \\
\hline 2018 & 0 & 3 & 1 & 0 \\
\hline 2019 & 1 & 1 & 4 & 3 \\
\hline 2020 & 4 & 10 & 1 & 3 \\
\hline TOTAL & & 24 & 0 \\
\hline
\end{tabular}

Fonte: Elaborado pelas autoras, 2020.

Analisando os dados encontrados é possivel identificar que a Revista Práxis Educacional se destaca com maior número de artigos, com publicações que se iniciam no ano de 2016 até 2020, visto que, em 2015 não foram encontrados estudos. A Revista Exitus possui dez publicações distribuídas entre quatro anos, pois em 2018 não houve pesquisas que abrangessem a temática. Além disso, a Revista Educação \& Formação contribuiu com quatro artigos, publicados nos anos de 2017, 2018, e 2020. Ademais, na Revista Tempos e Espaços em Educação foram identificados três artigos, ambos publicados no ano de 2019. 


\section{ALGUMAS CONSIDERAÇÕES}

Este estudo esteve alicerçado no objetivo de analisar a produção de artigos científicos que abordam a temática Educação do Campo em quatro revistas nacionais, a Revista Educação \& Formação, Revista Exitus, Revista Práxis Educacional e Revista Tempos e Espaços em Educação. Buscando compreender como estão sistematizadas as discussões acerca da educação do campo e suas políticas públicas educacionais, foi realizado um recorte temporal dos anos de 2015-2020, ou seja, investigados artigos publicados nos últimos cinco anos, pesquisando nos arquivos do site oficial de cada uma das revistas mencionadas.

No primeiro momento apresentamos um resgate histórico da Educação do Campo no Brasil e suas políticas públicas, posteriormente, realizada a análise do levantamento das publicações. Analisamos também as contribuições de diversos autores para compreender a Educação do Campo, em sua maioria nos estudos encontrados na pesquisa. Além disso, identificamos as políticas públicas educacionais e alguns marcos políticos da temática, bem como os artigos aos quais foram contempladas.

Assim, nas quatro revistas foram encontrados um total de 41 publicações, distribuídas entre os cinco anos pesquisados. A revista que possui mais publicações que abarca a temática em estudo é a Revista Práxis Educacional com 24 artigos, seguida pela Revista Exitus com 10. Em menor quantidade temos a Revista Educação \& Formação com 4 textos, e por fim, Tempos e Espaços em Educação com apenas 3 artigos. As publicações aconteceram em maior número em 2017, com 19 artigos que tratam da temática Educação do Campo, isso se deve ao fato que, a Revista Práxis Educacional publicou em 2017 o dossiê temático intitulado "Educação do Campo em Perspectiva Latino Americana", onde foram encontrados doze artigos.

Diversas contribuições foram encontradas nas produções que abarcam questões relacionadas às políticas públicas, como exemplo, os programas Procampo, Pronacampo e Pronera. Também analisam práticas 
pedagógicas, como as Escolas Famílias Agrícolas, Pedagogia da Alternância, cartas e história em quadrinhos como ferramentas pedagógicas. Além disso, há um destaque para artigos que investigam os movimentos sociais, suas contribuições, suas formas de ensinar e pensar sua educação.

Por fim, acredita-se que o número de artigos encontrados é significativo, mas não suficiente, pois a Educação do Campo se constitui enquanto uma temática relevante e inacabada. Neste estudo, foram encontrados diversos artigos que contribuem para pensar as políticas públicas e a prática pedagógica de uma Educação do/no Campo. Destarte, fazer pesquisa também é um movimento de resistência, quanto maior a quantidade de estudos mais visibilidade e impressões sobre a prática e as formas de pensá-la.

\section{REFERÊNCIAS}

ALVES, A. I. O jeito CPT de fazer formação: a Comissão Pastoral da Terra ensina e aprende com trabalhadores rurais. Revista Práxis Educacional, Vitória da Conquista, v. 13, n. 26, p.181-195, set./dez. 2017. Disponvel em: <http://periodicos2.vesb.br/index.php/praxis/article/view/2826/3813>. Acesso em: 20 maio 2020.

ARROYO, M. G.; FERNANDES, B. M. A educação básica e o movimento social do campo. Braślia, DF: Articulação Nacional por uma Educação do Campo, 1999. Coleção por uma Educação Básica do Campo nº 2.

BARBOSA, L. P.; ROSSET, P. M. Movimentos Sociais e Educação do Campo na América Latina: aprendizagens de um percurso histórico. Revista Práxis Educacional, Vitória da Conquista, v. 13, n. 26, p. 22-48, set./dez. 2017. Disponível em:

<http://periodicos2.vesb.br/index.php/praxis/article/view/2819/3820 >. Acesso em: 20 maio 2020.

BORGES, H. da S.; OLIVEIRA, B. da S. Os pontos convergentes entre os/as teóricos/as da educação do campo. Práxis Educacional, v. 16, n. 39, p. 238258, abr. 2020. ISSN 2178-2679. Disponível em:

<http://periodicos2.vesb.br/index.php/praxis/article/view/6376>. Acesso em: 20 maio 2020.

BRASIL. Lei $\mathbf{n}^{\circ}$ 12.960, de 27 de março de 2014. Altera a Lei no 9.394, de 20 de dezembro de 1996, que estabelece as diretrizes e bases da educação nacional, para fazer constar a exigência de manifestação de órgão 
normativo do sistema de ensino para o fechamento de escolas do campo, indígenas e quilombolas. Brasília, 2014. Disponível em:

<https://www2.camara.leg.br/legin/fed/lei/2014/lei-12960-27-marco-2014778312-publicacaooriginal-143651-pl.html>. Acesso em: 20 maio 2020.

BRASIL. Resolução CEE $n^{\circ}$ 103, de 28 de setembro de 2015. Dispõe sobre a oferta da Educação do Campo, no Sistema Estadual de Ensino da Bahia. Disponível em:

<https://forumdeeducacaodocamporj.blogspot.com/2016/03/resolucaocee-n-103-de-28-de-setembro.html>. Acesso em: 20 maio 2020.

BRASIL. Resolução CNE/CEB n 1, de 03 abril de 2002. Diretrizes Operacionais para a Educação Básica nas Escolas do Campo. Disponível em: <http://portal.mec.gov.br/escola-de-gestores-da-educacao-basica/323secretarias- 11 2877938/orgaos-vinculados-82187207/13200-resolucao-ceb2002>. Acesso em: 20 maio 2020.

BRASIL. Resolução CNE/CEB n² 2, de 28 de abril de 2008. Diretrizes Operacionais para a Educação Básica nas Escolas do Campo. Disponível em: <http://portal.mec.gov.br/escola-de-gestores-da-educacao-basica/323secretarias- 11 2877938/orgaos-vinculados-82187207/13200-resolucao-ceb2002>. Acesso em: 20 maio 2020.

BRASIL. Decreto $\mathbf{n}^{\circ}$ 7.352, de 4 de novembro de 2010. A política de educação do campo e o Programa Nacional de Educação na Reforma Agrária PRONERA. Disponível em:< http://www.planalto.gov.br/ccivil_03/_ato20072010/2010/decreto/d7352.htm>. Acesso em: 20 maio 2020.

CALDART, R. S. Educação do Campo: notas para uma análise de percurso. Trab. Educ. saúde, Rio de Janeiro, v.7 n¹, p 35-64, mar/jun. 2009.

CARVALHO, R. A. de. A construção da identidade e da cultura dos povos do campo, entre o preconceito e a resistência: o papel da educação. Tese (Doutorado em Educação), Programa de Pós-Graduação em Educação da Universidade Metodista de Piracicaba - UNIMEP. Piracicaba, São Paulo, 2011

CORRÊA, S. R. M.; NASCIMENTO, M. D. F. DO. MST, agroecologia e educação do campo na Amazônia: um estudo sob o enfoque das epistemologias do sul. Revista Tempos e Espaços em Educação, v. 12, n. 29, p. 299-324, 13 jun. 2019. Disponível: < https://seer.ufs.br/index.php/revtee/article/view/9346 >. Acesso em: 20 maio 2020.

COSTA, H. G. P. da; LOMBA, R. M. Educação do campo e desafios amazônicos: o PRONERA no Estado do Amapá. Revista Exitus, Santarém/PA, Vol. 7, N 1, p. 224-249, Set/Dez 2017. Disponível em: <http://ufopa.edu.br/portaldeperiodicos/index.php/revistaexitus/article/view 1355>. Acesso em: 25 de janeiro de 2020. 
CUNHA, A. M.; MAYNARD, D. C. S. "Educando com o livro e a enxada": Robert King Hall e o Programa de Educação Rural do INEP (1949-1951).

Revista Práxis Educacional, Vitória da Conquista-Bahia-Brasil, v. 15, n. 33, p. 338-353, jul./set. 2019. Disponível em: <

http://periodicos2.uesb.br/index.php/praxis/article/view/5307/3991>. Acesso em: 30 maio 2020.

FERREIRA, L. G.; ANUNCIATO, R. M. M. Cartas que revelam a vida: histórias de professores iniciantes da zona rural. Revista Práxis Educacional, Vitória da Conquista - Bahia - Brasil, v.14, n. 30, p. 229-246, out./dez. 2018. Disponível em: < http://periodicos2.uesb.br/index.php/praxis/article/view/4369/3496 >. Acesso em: 30 maio 2020.

FERREIRA, F. de J.; BRANDÃO, E. C. Educação do campo: um olhar histórico, uma realidade concreta. Revista Eletrônica de Educação. Ano V. No. 09, jul./dez. 2011.

FERNANDES, B. M. F. Diretrizes de uma caminhada. In: ARROYO, M. G.; CALDART, R. S.; MOLINA, M. C. (Orgs.). Por uma educação do campo. 3 ed. Petrópolis, RJ: Vozes, 2008.

FERREIRA, N. S. de A. As pesquisas denominadas "Estado da Arte". Educação \& Sociedade, ano XXIII, n 79, Agosto/2002.

FREIRE, P. Pedagogia da autonomia: saberes necessários à prática educativa. São Paulo: Paz e Terra, 1996. - (Coleção Leitura). 25ª edição.

FONSECA, E. M. de; BIERHALZ, C. D. K. O contexto local como elo entre ciências da natureza e educação do campo. Educação \& Formação, Fortaleza, v.3, n.7, p. 66-84, jan./abr. 2018.

FRAGA, R. C. Q.; SOUSA, J. R. F. de. Pedagogia da Alternância e prática educativa na educação do campo: experiência da escola família agrícola Dom Fragoso no Ceará. Revista Práxis Educacional, Vitória da Conquista, v. 13, n. 26, p.196-216, set./dez. 2017. Disponível em: <http://periodicos2.uesb.br/index.php/praxis/article/view/2827/3814>. Acesso em: 30 maio 2020.

FREITAS, G. R.; SOUZA, R. R. de. Estado, Política e Educação do Campo: uma revisão de conceitos á luz da pedagogia histórico crítica. Revista Exitus Santarém, PA, Vol. 5, Nº 2, P. 101-113, Jul./Dez.2015. Disponível em: < http://ufopa.edu.br/portaldeperiodicos/index.php/revistaexitus/article/view/ 63 >. Acesso em: 30 de abril de 2020.

GOHN, M. da G. Teoria dos movimentos sociais paradigmas clássicos e contemporâneos. Edições Loyola. São Paulo: 1997. 
JUNQUEIRA, V. H.; BEZERRA. M. C. dos S. A quem interessa a educação dos trabalhadores do campo? uma análise do Pronacampo. Revista Exitus, Santarém, PA, Vol. 5, № 2, p. 83 -100, Jul./Dez.2015. Disponível em: <http://ufopa.edu.br/portaldeperiodicos/index.php/revistaexitus/article/view 161>. Acesso em: 30 de abril de 2020.

MORETTI, C. Z.; VERGUTZ, C. L. B.; COSTA, J. P. R. "Chama a Roda" na Escola Família Agrícola de Santa Cruz do Sul: o círculo de cultura reinventado na pedagogia da alternância. Revista Práxis Educacional, Vitória da Conquista, v. 13, n. 26, p. 217-235, set./dez. 2017. Disponível em: <http://periodicos2.uesb.br/index.php/praxis/article/view/2828/3815>. Acesso em: 30 maio 2020.

NUNES, K. de C. S.; NETO, L. B. Urbano e rural: contradições e influências no (re) pensar da ruralidade no Brasil. Revista Exitus, Santarém, PA, Vol. 6, N ${ }^{\circ} 1$, p. 62 - 76, Jan./Jun.2016. Disponível em:

<http://ufopa.edu.br/portaldeperiodicos/index.php/revistaexitus/article/view /39>. Acesso em: 30 de abril de 2020.

PEREIRA, C. C.; SOUZA, M. A. de. A Política de Fechamento de Escolas no Campo na Região Metropolitana de Curitiba/PR. Práxis Educacional, [S.I.], v. 13, n. 26, mar. 2018. ISSN 2178-2679. Disponível em:

<http://periodicos2.vesb.br/index.php/praxis/article/view/2825>. Acesso em: 30 maio 2020. Doi: https://doi.org/10.22481/praxis.v13i26.2825.

RIBEIRO, M. Pedagogia da alternância na educação rural/do campo: projetos em disputa. Educação e Pesquisa, São Paulo, v.34, n.1. jan./abr, 2008.

RODRIGUES, M. E. Audição radiofônica em uma comunidade rural na Amazônia paraense. Revista Exitus, Santarém/PA, Vol. 9, № 1, p. 340 - 366 , JAN/MAR 2019. Disponível em:

<http://ufopa.edu.br/portaldeperiodicos/index.php/revistaexitus/article/view /726>. Acesso em: 15 de abril de 2020.

ROMANOWSKI, J. P.; ENS, R. T. As pesquisas denominadas do tipo "Estado da arte" em Educação. Diálogo Educ., Curitiba, v. 6, n.19, p.37-50, set./dez. 2006.

SAMBORSKI, T. Ruralidade e sociedade em rede. Revista Exitus, Santarém, PA Vol. 6, N N 1, p. 199 - 210, Jan./Jun.2016. Disponível em: <http://ufopa.edu.br/portaldeperiodicos/index.php/revistaexitus/article/view |49>. Acesso em: 10 de maio de 2020.

SANTOS, A. R. dos. Educação do Campo e Agronegócio: Território de Disputas. Educação em Revista, Marília, v.18, n.2, p. 71-90, Jul.-Dez., 2017. 
SANTOS, A. R. dos; CARVALHO, M. dos S. O Pronera como política pública educacional do campo: contextos e contradições. Rev. Tempos Espaços Educ. São Cristóvão, Sergipe, Brasil, v. 12, n. 31, p. 275-296, out./dez. 2019. Disponível em: https://seer.ufs.br/index.php/revtee/article/view/11466/pdf. Acesso em: 20 maio 2020.

SANTOS, M.; FETZNER, A. R. PROCAMPO: field education policy. Revista Tempos e Espaços em Educação, v. 12, n. 30, p. 189-206, 8 ago. 2019.

SILVA, E. M. da; ARAÚJO, G. C. de. Compreensão de textos verbais e visuais a partir da produção de histórias em quadrinhos com jovens e adultos camponeses. Revista Exitus, Santarém/PA, Vol. 9, № 3, p. 578 - 605, JUL/SET 2019. Disponível em:

<http://ufopa.edu.br/portaldeperiodicos/index.php/revistaexitus/article/view 1928>. Acesso em: 11 de janeiro de 2020.

SILVA, N.; SILVA, J. D.; COSTA, R. O jogo em turmas multisseriadas de escolas rurais: auxílio à adoção de regras essenciais à vida. Educação \& Formação, v. 5, n. 14mai/ago, 20 jan. 2020.

VASCONCELOS, M. O.; XIMENES MIRANDA NUNES, M. C.; XIMENES-ROCHA, S. H. Educação integral de tempo integral: diagnóstico da implantação em escola do campo. Práxis Educacional, [S.I.], v. 15, n. 32, p. 337-357, maio 2019. ISSN 2178-2679. Disponível em:

<http://periodicos2.vesb.br/index.php/praxis/article/view/5058>. Acesso em: 20 maio 2020.

Recebido em: 02 de março de 2019 Aprovado em: 20 de maio de 2020 Publicado em: 14 de agosto de 2020 